American Journal of Pharmacology and Toxicology 7 (2): 49-61, 2012

ISSN 1557-4962

(C) 2012 Science Publications

\title{
Effect of New Compound with Antioxidant Potential in the Energy Metabolism of Adults Rats after Pneumococcal Meningitis
}

\author{
${ }^{1}$ Barichello, T., ${ }^{1}$ Geovana Dagostim Savi, ${ }^{1}$ A.P. Panatto, ${ }^{1}$ J.S. Generoso, ${ }^{1}$ A.L. Cipriano, \\ ${ }^{2}$ G.T. Rezin, ${ }^{2}$ F. Dal-Pizzol, ${ }^{2}$ E.L. Streck, ${ }^{3}$ F. Petronilho, ${ }^{4}$ L. Vidal and ${ }^{4}$ M. Geffard \\ ${ }^{1}$ Laboratório de Microbiologia Experimental and Instituto, \\ Nacional de Ciência e Tecnologia Translacional em Medicina, \\ Programa de Pós-Graduação em Ciências da Saúde, \\ Unidade Acadêmica de Ciências da Saúde, Universidade do Extremo Sul Catarinense, \\ Avenida Universitária, Universitário, 88806-000, Criciúma, SC, Brazil \\ ${ }^{2}$ Laboratório de Fisiopatologia and Instituto Nacional de Ciência e Tecnologia \\ Translacional em Medicina, Programa de Pós-Graduação em Ciências da Saúde, Unidade \\ Acadêmica de Ciências da Saúde, \\ Universidade do Extremo Sul Catarinense, Criciúma, SC, Brazil \\ ${ }^{3}$ Laboratório de Imunopatologia Experimental, Programa de Pós-Graduação \\ em Ciências da Saúde, Universidade do Sul de Santa Catarina, Criciuma, SC, Brazil \\ ${ }^{4}$ IDRHT, Instituto de Desenvolvimento e Pesquisa \\ de Patologias Humanas e Novas Terapias, \\ Laboratório de Sistemas e Integração de Materiais (ISM), \\ École Pratique des Hautes Études, Talence, Franca
}

\begin{abstract}
Problem statement: In bacterial meningitis, the Streptococcus pneumoniae can modify the cerebro-spinal fluid (CSF) homeostasis and initiation of the host inflammatory response with presence cytokine and leukocyte migration into the subarachnoidal space. Despite the availability of highly effective antibiotics, the disease is often fatal or causes long-term neurological problems in affected patients. Approach: The aim of this study was to evaluate the effect of this new compound P0801 in the oxidative stress, mitochondrial respiratory chain and brain Creatine Kinase activity (CK) in adult rats after meningitis by S.pneumoniae. Results: In our study, the group of animals with pneumococcal meningitis that received P0801, with or without antibiotic therapy at $24 \mathrm{~h}$ after induction decreased protein carbonyls in cerebral cortex and in the hippocampus at $48 \mathrm{~h}$ after induction, being that the same time decreased lipid peroxidation. In the animals that received antibiotic therapy and or treatment with P0801 at $24 \mathrm{~h}$ after induction of meningitis, there were increased by the activity of complex I, II, IV and enzyme succinate dehydrogenase in cerebral cortex, being that at $48 \mathrm{~h}$ in the group that received antibiotic therapy and or P0801, there were increased by the activity of complex I, II and succinate dehydrogenase in the cerebral cortex and or hippocampus. In our study, the CK activity was increased in hippocampus and cerebral cortex at $24 \mathrm{~h}$ after induction meningitis in the group that received antioxidant treatment and only in cerebral cortex in the group that received antibiotic therapy with antioxidant treatment. Conclusion/Recommendations: The study with new compound is an attempt to coadjuvant treatment with the antibiotic to minimize the oxidative damage and energy metabolism during illness. New studies are needed to clarify the action of this new compound as coadjuvant, evaluating side effects and their formulation, since it might look promising in the development of novel therapeutic agents in further studies.
\end{abstract}

Key words: Streptococcus pneumoniae, meningitis, energy metabolism, oxidative damage, antioxidant treatment, cerebral cortex, hippocampus

Corresponding Author: Geovana Dagostim Savi, Laboratório de Microbiologia Experimental and Instituto, Nacional de Ciência e Tecnologia Translacional em Medicina, Programa de Pós-Graduação em Ciências da Saúde, Unidade Acadêmica de Ciências da Saúde, Universidade do Extremo Sul Catarinense, Avenida Universitária, Universitário, 88806-000, Criciúma, SC, Brazil 


\section{INTRODUCTION}

Pneumococcal Meningitis (PM) are characterized by an intense inflammatory host reaction of the central nervous system that contributes to the development of cortical necrosis and hippocampal apoptosis (Bellac et al., 2006). The highest rate of learning deficits in founding in meningitis caused by Streptococcus pneumoniae compared with other infecting agents as Haemophilus influenza or group B Streptococcus (Merkelbach et al., 2000; Bedford et al., 2001; Beek et $a l ., 2002)$. The $S$. pneumoniae is the cause of the most severe and most frequent form of adult bacterial meningitis. The microorganism can modify the cerebrospinal fluid (CSF) homeostasis and initiation of the host inflammatory response with presence cytokine and leukocyte migration into the subarachnoidal space (Quagliarello et al., 1991; Ostergaard et al., 2000; Koedel et al., 2002). Because of this may occur increase the release of metabolites proteolytic as reactive oxygen species (ROS), resulting in endothelial damage and increased permeability of blood brain barrier (BBB). The production of ROS can contribute neuroinflammatory process and has an important role in the pathophysiology of bacterial meningitis can cause inhibition of activity of complexes of the enzymes of mitochondrial respiratory chain, inactivation of glyceraldehyde-3-phosphate dehydrogenase, inhibition of $\mathrm{Na}^{+}, \mathrm{K}^{+}$-ATPase and decreased in cellular energy metabolism (Cuzzocrea et al., 2001). The inflammatory host response can to contribution altered brain physiology, BBB breakdown, brain edema, increasing intracranial pressure and brain injury (Brandt, 2010). Inflammation contributes to morbidity and mortality, but is itself unresponsive to antibiotics. Therapy with antibiotics is only partially effective in preventing mortality and development of neurological sequelae caused by pneumococcal meningitis. Despite the availability of highly effective antibiotics, the disease is often fatal or causes long-term neurological problems in affected patients (Baraff et al., 1993; Grimwood et al., 1995). Therefore, new adjunctive therapies that may modulate the inflammatory process are needed (Koedel et al., 2002; Scheld et al., 2002).

In this study, was to evaluate the effect of a new compound P801, containing fatty acids with poly-L-lysine, cysteine, retinoic acid, coenzyme Q10, ascorbic acid, taurine, methionine and alpha-tocopherol with potential antioxidant activity in the oxidative stress, mitochondrial respiratory chain and brain Creatine kinase activity in adult rats after meningitis by $S$. pneumoniae.

\section{MATERIALS AND METHODS}

Animals: Male Wistar rats (300 $\mathrm{g}$ of body weight) were obtained from our breeding colony. The animals were housed five to a cage with food and water available $a d$ libitum and were maintained on a normal 12-h light/dark cycle. All procedures were approved by the Animal Care and Experimentation Committee of the UNESC, Brazil and followed in accordance with the National Institute of Health Guide for the Care and Use of Laboratory Animals (NIH Publications No. 80-23) revised in 1996.

An animal model of meningitis: All surgical procedures and bacteria inoculations were performed under anesthesia, consisting of an intraperitoneal administration of ketamine $\left(6.6 \mathrm{mg} \mathrm{kg}^{-1}\right)$, xylazine $(0.3$ $\left.\mathrm{mg} \mathrm{kg}{ }^{-1}\right)$ and acepromazine $\left(0.16 \mathrm{mg} \mathrm{kg}^{-1}\right.$ ) (Hoogman et al., 2007; Bellac et al., 2007; Grandgirard et al., 2007). S. pneumoniae (ATCC 6303) was cultured overnight in Todd Hewitt broth and grown to logarithmic phase. In the morning of the experiment the culture was centrifuged for $10 \mathrm{~min}$ at $(5000 \times \mathrm{g})$ and resuspended in sterile saline to the concentration $5 \times 10^{9}$ CFU/mL (Grandgirard et al., 2007; Irazuzta et al., 2008). Rats underwent a cisterna magna tap with a 23gauge needle. The position of the needle was verified by the free flow of clear cerebro-spinal fluid. CSF was withdrawn and the animals received either $10 \mu \mathrm{L}$ of sterile saline as a placebo (sham) or an equivalent volume of the $S$. pneumoniae. At the time of inoculation, the animals received fluid replacement (10 $\mathrm{mL}$ of saline subcutaneously) and were returned to their cages (Irazuzta et al., 2008). Following their recovery from anesthesia, the animals were supplied with food and water ad libitum. Meningitis was documented $16 \mathrm{~h}$ after induction of the meningitis by a quantitative culture of $5 \mu \mathrm{L}$ of CSF obtained by puncture of the cisterna magna and cultured quantitatively on sheep blood agar plates to document that they had meningitis (Bellac et al., 2007; Grandgirard et al., 2007). The animals received antibiotic therapy beginning at $16 \mathrm{~h}$ after induction (ceftriaxone, $100 \mathrm{mg} \mathrm{kg}{ }^{-1}$ body weight twice a day intraperitoneally) and antioxidant treatment with a new compound P0801 $\left(6,87 \mathrm{mg} \mathrm{kg}^{-1}\right.$ body weight twice a day intraperitoneally). The animals were killed by decapitation at $24 \mathrm{~h}$ and $48 \mathrm{~h}$ after inoculation (Bellac et al., 2007; Grandgirard et al., 2007). The brain was removed and hippocampus and cerebral cortex were isolated and stored at $-80^{\circ} \mathrm{C}$.

Determination of lipid peroxidation and carbonyl groups: As an index of lipid peroxidation, we used the formation of thiobarbituric acid reactive species (TBARS) during an acid-heating reaction (Draper and Hadley, 1990). Briefly, the samples were mixed with 1 $\mathrm{mL}$ of $10 \%$ trichloroacetic acid and $1 \mathrm{~mL}$ of $0.67 \%$ thiobarbituric acid and then heated in a boiling water bath for $30 \mathrm{~min}$. TBARS were determined based on absorbance at $532 \mathrm{~nm}$. The oxidative damage to 
Am. J. Pharm. \& Toxicol., 7 (2): 49-61, 2012

proteins was assessed by the determination of carbonyl groups based on the reaction with dinitrophenylhidrazine (DNPH), as previously described (Levine et al., 1990). Briefly, proteins were precipitated by the addition of $20 \%$ trichloroacetic acid and redissolved in DNPH and the absorbance was monitored at $370 \mathrm{~nm}$.

Activities of mitochondrial respiratory chain enzymes: Hippocampus and cerebral cortex were homogenized $(1: 10, \mathrm{w} / \mathrm{v})$ in SETH buffer, $\mathrm{pH} 7.4$ (250mM sucrose, $2 \mathrm{mM}$ EDTA, 10mM Trizma base, 50 $\mathrm{IU} \mathrm{mL}^{-1}$ heparin). The homogenates were centrifuged at $800 \times \mathrm{g}$ for $10 \mathrm{~min}$ and the supernatants kept on $-80^{\circ} \mathrm{C}$ until used for the enzyme activity determination. The maximal period between homogeneous preparation and enzyme analysis was always less than 5 days. Activities of mitochondrial respiratory chain enzymes: NADH dehydrogenase (complex I) was evaluated according to the method described by Cassina and Radi (1996) by the rate of NADH-dependent ferricyanide reduction at 420 $\mathrm{nm}$. The activities of succinate-2,6-Dichloroindophenol (DCIP)- oxidoreductase (complex II) and Succinate Dehydrogenase (SDH) was determined by the method described by Fischer et al. (1985). Complex II activity was measured by following the decrease in absorbance due to the reduction of 2,6-DCIP at $600 \mathrm{~nm}$. SDH activity was measured by following the decrease in absorbance due to the reduction of $2,6-$ DCIP at $600 \mathrm{~nm}$ in the presence of phenazine methasulphate. The activity of succinate: cytochrome c oxidoreductase (complex III) was determined according to the method of Fischer et al. (1985). Complex III activity was measured by cytochrome c reduction using succinate as substrate at $550 \mathrm{~nm}$. The activity of cytochrome c oxidase (complex IV) was assayed according to the method described by Rustin et al. (1994), measured by following the decrease in absorbance due to the oxidation of previously reduced cytochrome $\mathrm{c}$ at $550 \mathrm{~nm}$. The activities of the mitochondrial respiratory chain complexes were expressed as nmol. $\mathrm{Min}^{-1}$. mg protein ${ }^{-1}$.

Creatine Kinase (CK) activity assay: Creatine kinase activity was measured in brain homogenates pre-treated with $0.625 \mathrm{mM}$ lauryl maltoside. The reaction mixture consisted of $60 \mathrm{mM}$ Tris- $\mathrm{HCl}, \mathrm{pH}$ containing 7.5, $\mathrm{mM}$ phosphocreatine, $9 \mathrm{mM} \mathrm{MgSO}_{4}$ and approximately $0.4-$ $1.2 \mu \mathrm{g}$ protein in a final volume of $100 \mu \mathrm{L}$. After 15 min of pre-incubation at $37^{\circ} \mathrm{C}$, the reaction was started by the addition of $3.2 \mu \mathrm{mol}$ of ADP plus $0.8 \mu \mathrm{mol}$ of reduced glutathione. The reaction was stopped after 10 min by the addition of $1 \mu \mathrm{mol}$ of $\mathrm{p}$ hydroxymercuribenzoic acid. The creatine formed was estimated according to the colorimetric method of Hughes (1962). The color was developed by the addition of $100 \mu \mathrm{L} 2 \% \mu$-naphtol and $100 \mu \mathrm{L} 0.05 \%$ diacetyl in a final volume of $1 \mathrm{~mL}$ and read spectrophotometrically after $20 \mathrm{~min}$ at $540 \mathrm{~nm}$. Results were expressed as nmol. min $^{-1}$. $\mathrm{mg}_{\text {protein }}{ }^{-1}$.

Protein content: The protein content was determined by the method described by Lowry et al. (1951) using bovine serum albumin as standard.

Statistical analysis: The data oxidative stress were Analyzed Using Analysis of Variance (ANOVA) followed by post hoc Tukey and the data mitochondrial respiratory chain enzymes and Creatine Kinase (CK) activity were analyzed followed by Student's t test. All analyses were expressed as mean \pm S.D. and were performed using the Statistical Package for the Social Science (SPSS) software version 17.0.

\section{RESULTS}

In the cerebral cortex of animals with pneumococcal meningitis decreased protein carbonyls in the group that received antioxidant treatment with new compound P0801, with or without antibiotic therapy at $24 \mathrm{~h}$ after induction. In the hippocampus there was not altered (Fig 1a). In the group that received only antibiotic therapy increased protein carbonyls in the hippocampus, however, in the group that received antioxidant treatment there was decreased protein carbonyls at $48 \mathrm{~h}$ after induction meningitis, being that in the cerebral cortex there was not altered (Fig. 1b).

In the group that received only antioxidant treatment increased lipid peroxidation in the cerebral cortex at $24 \mathrm{~h}$ after induction meningitis, being that in the hippocampus there was not altered (Fig. 2a). In the Fig $2 b$ shows decreased lipid peroxidation in the group that received only antioxidant treatment in hippocampus at $48 \mathrm{~h}$ after induction meningitis, being that in the cerebral cortex there was not altered.

In the animals with pneumococcal meningitis that received antibiotic therapy or antioxidant treatment with new compound $\mathrm{P} 0801$ at $24 \mathrm{~h}$ after induction of meningitis, the activity of complex I in cerebral cortex was increased in the group that received antibiotic therapy and antioxidant treatment (Fig. 3a), being that in $48 \mathrm{~h}$ was increased in the group that received only antioxidant treatment (Fig. 4a). The activity of complex II in cerebral cortex was increased in the group that received antioxidant treatment at $24 \mathrm{~h}$ (Fig. 3b) and at 48 $\mathrm{h}$ in the hippocampus also (Fig. 4b). The activity of complex III there was not altered at 24 and $48 \mathrm{~h}$ after induction meningitis (Fig. $3 \mathrm{c}$ and $4 \mathrm{c}$ ). The activity of complex IV was increased in the cerebral cortex at $24 \mathrm{~h}$ after induction meningitis in the group that received antioxidant treatment and in the group that received antioxidant treatment and antibiotic therapy (Fig. 3d). At $48 \mathrm{~h}$ there was not altered (Fig. $4 \mathrm{~d}$ ). 

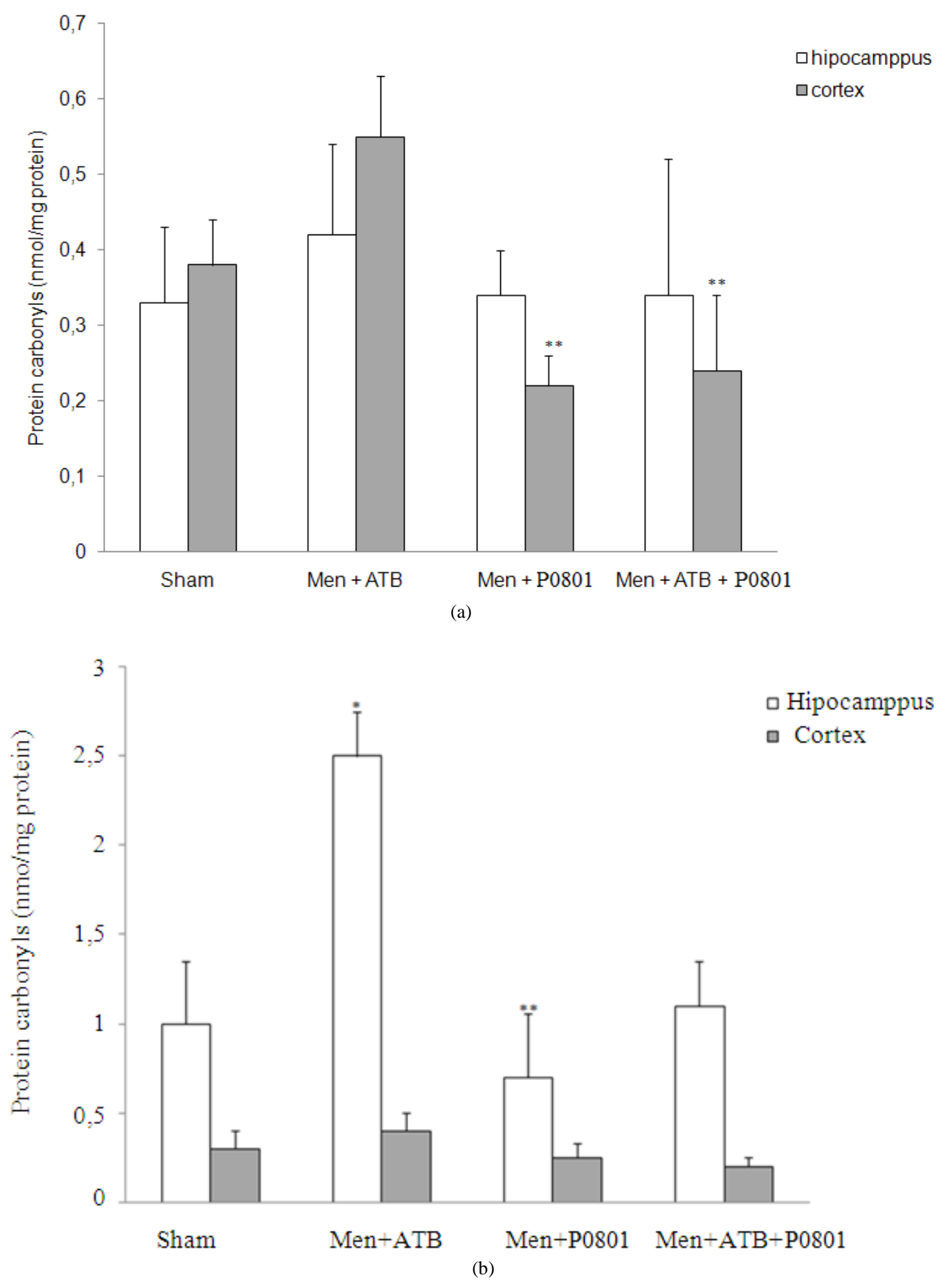

Fig. 1: Protein carbonyls in the hippocampus and cerebral cortex of rats after pneumococcal meningitis that received antibiotic therapy or antioxidant treatment with P0801 at $24 \mathrm{~h} \mathrm{(A)}$ and at $48 \mathrm{~h}$ (B) after induction of meningitis. Results are expressed as mean \pm S.D. of 5 animals in each group. Symbols indicate statistically significant when compared with sham group $* \mathrm{p}<0.05$, $* * \mathrm{p}<0.05$ when compared with meningitis group that receive antibiotic therapy and $* * * p<0.05$ when compared with meningitis group that received antibiotic therapy and antioxidant treatment 
Am. J. Pharm. \& Toxicol., 7 (2): 49-61, 2012

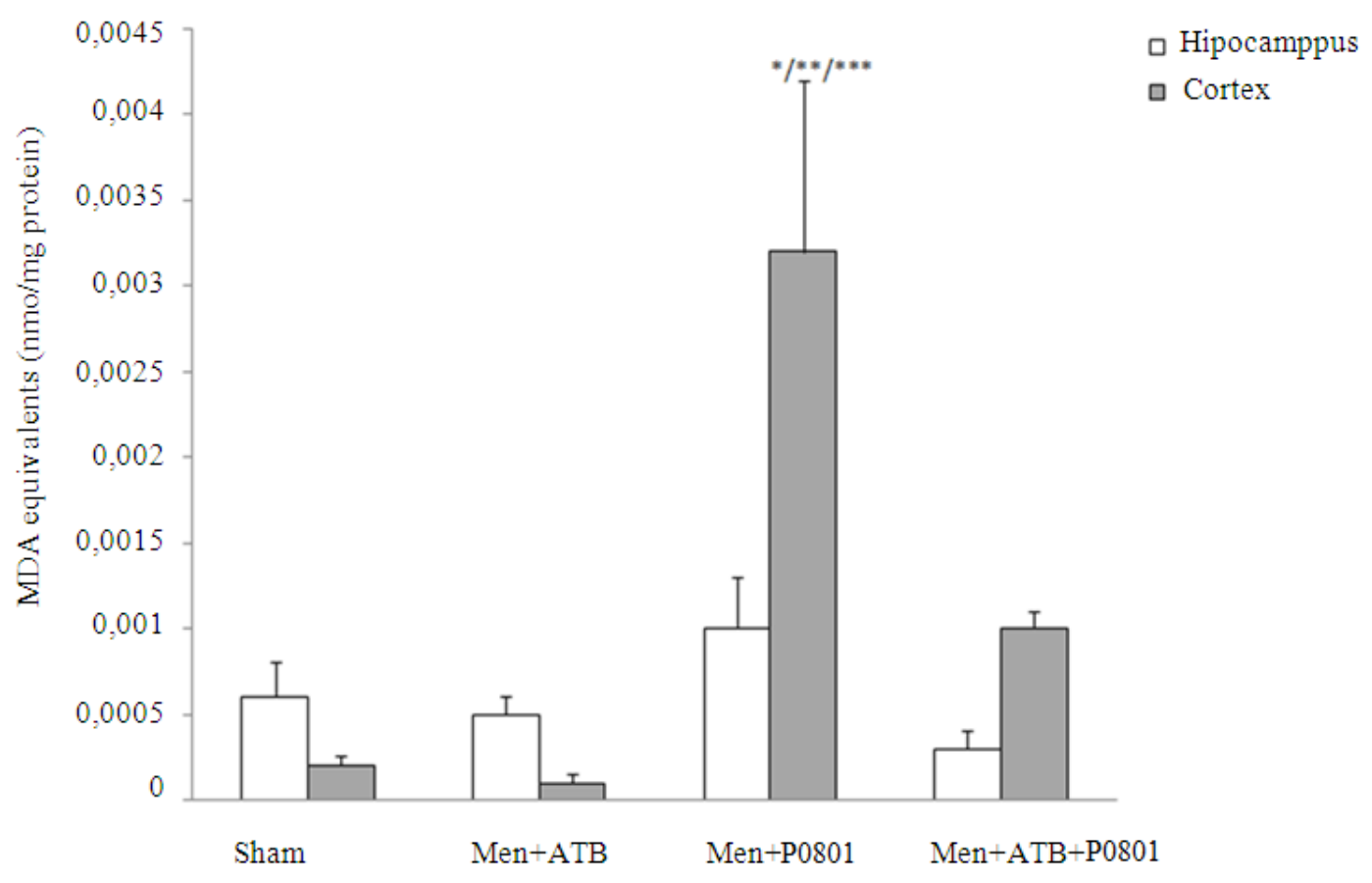

(a)

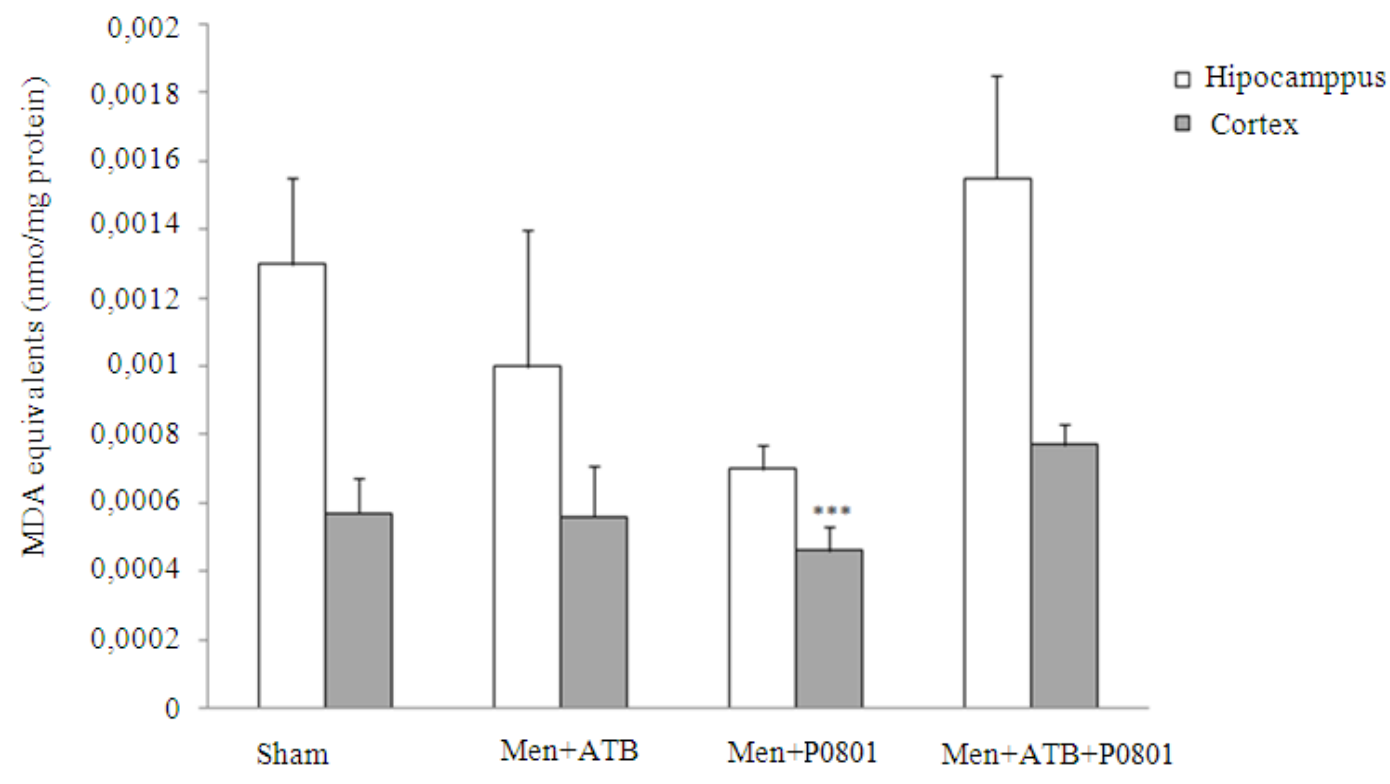

(b)

Fig. 2: Lipid peroxidation in the hippocampus and cerebral cortex of rats after pneumococcal meningitis that received antibiotic therapy or antioxidant treatment with P0801 at $24 \mathrm{~h} \mathrm{(A)}$ and at $48 \mathrm{~h} \mathrm{(B)}$ after induction of meningitis. Results are expressed as mean \pm S.D. of 5 animals in each group. Symbols indicate statistically significant when compared with sham group $* \mathrm{p}<0.05,{ }^{* *} \mathrm{p}<0.05$ when compared with meningitis group that receive antibiotic therapy and $* * * \mathrm{p}<0.05$ when compared with meningitis group that received antibiotic therapy and antioxidant treatment 
Am. J. Pharm. \& Toxicol., 7 (2): 49-61, 2012

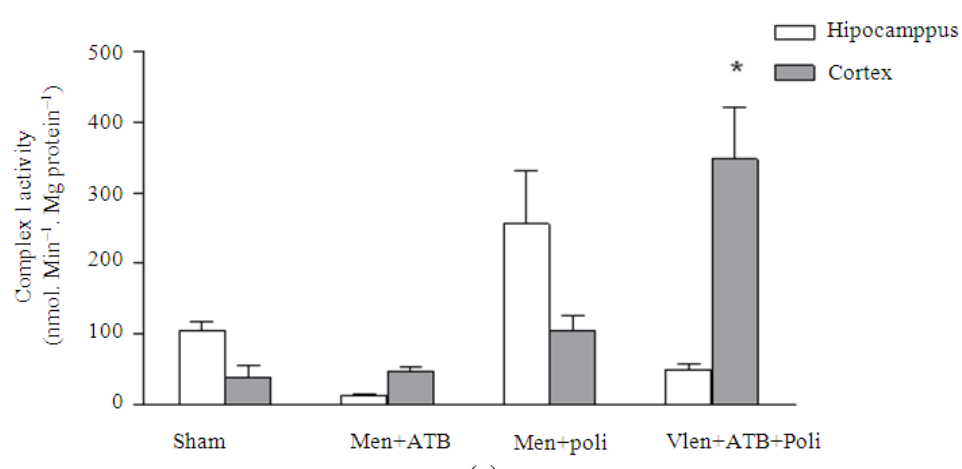

(a)

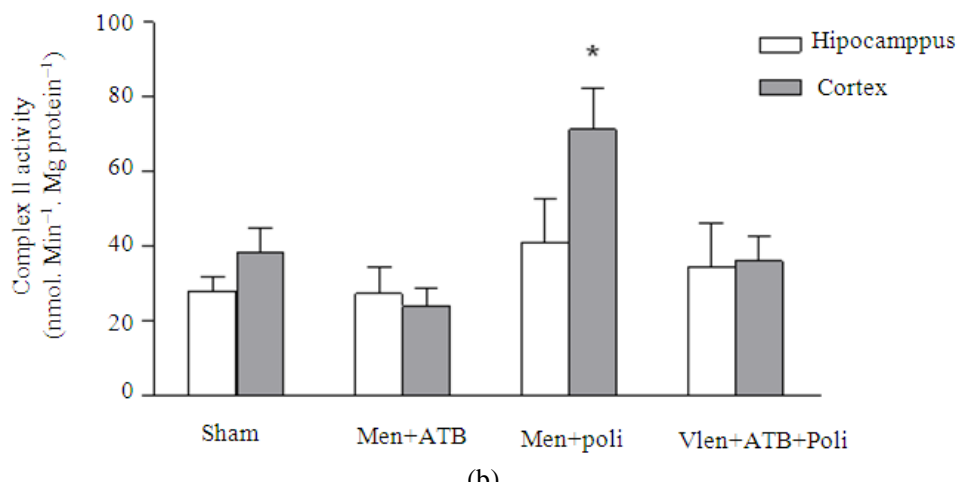

(b)

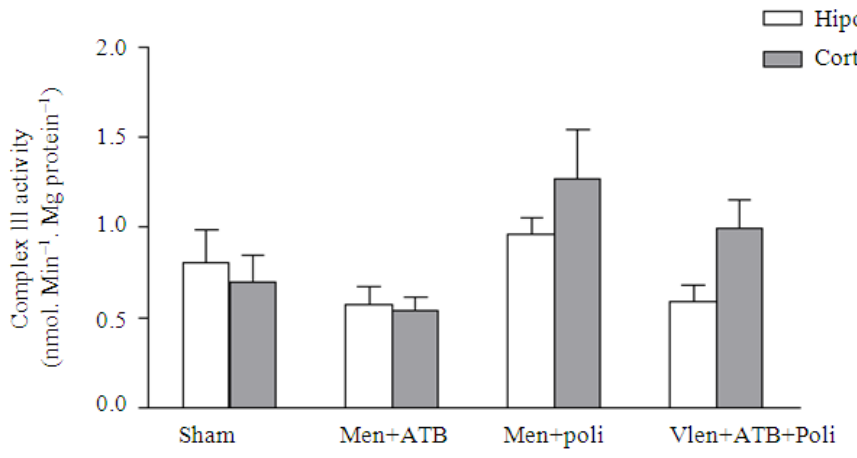

(c)

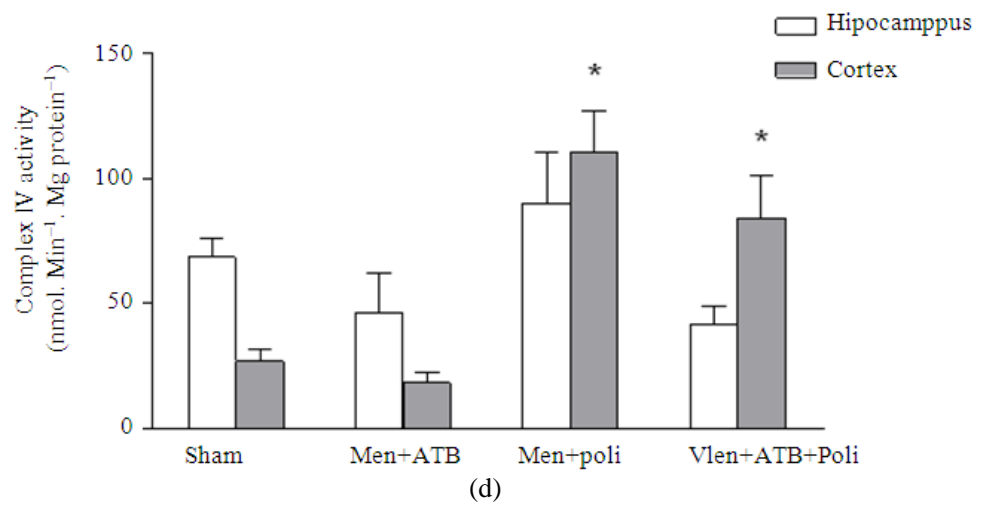




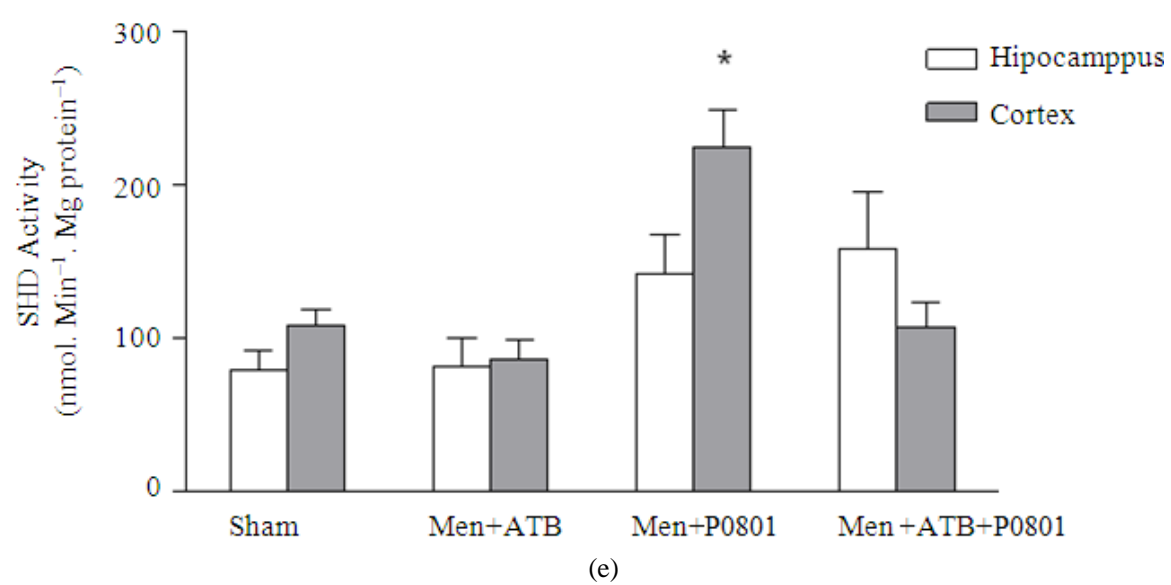

Fig. 3: Activity of complexes I (A), II (B), III (C), IV (D) and SDH (E) in the hippocampus and cerebral cortex of rats after pneumococcal meningitis that received antibiotic therapy or antioxidant treatment with P0801 at 24 $\mathrm{h}$ after induction of meningitis. Results are expressed as mean \pm S.D. of 5-7 animals in each group. Symbols indicate statistically significant when compared with sham group *p $<0.05$

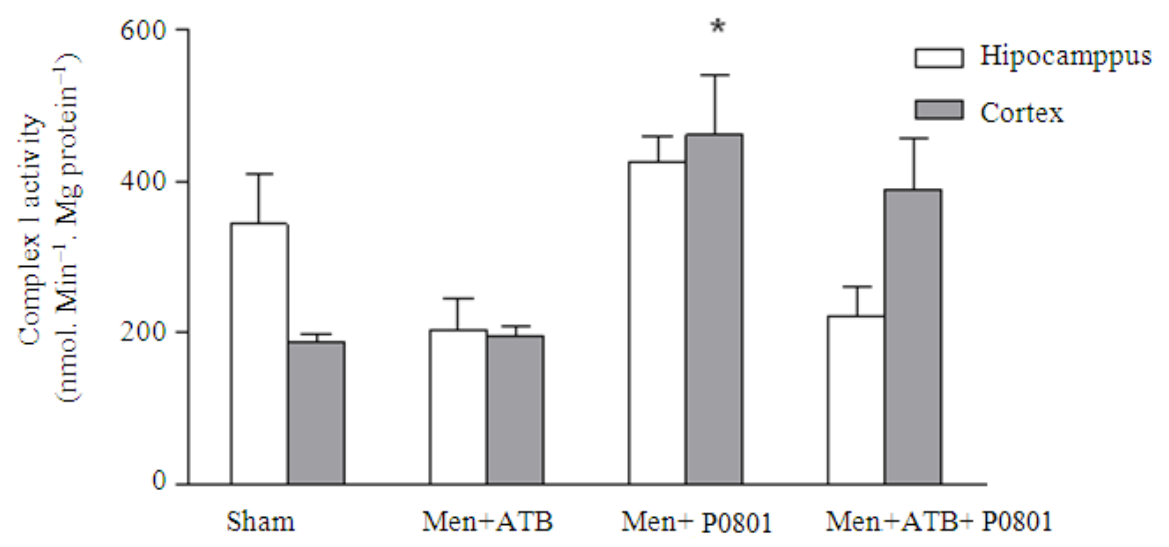

(a)

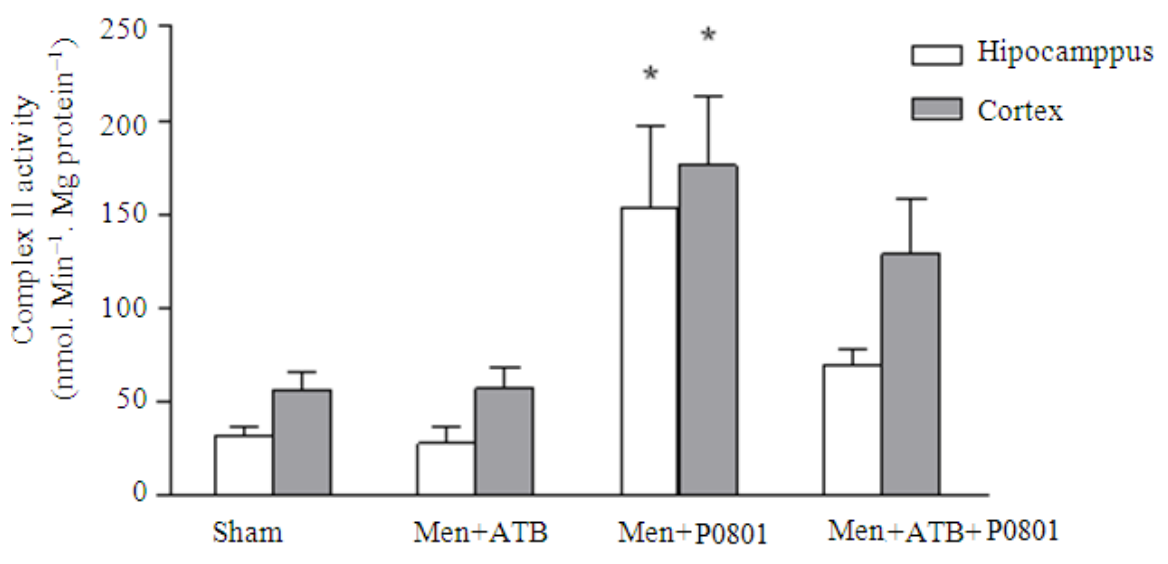

(b) 

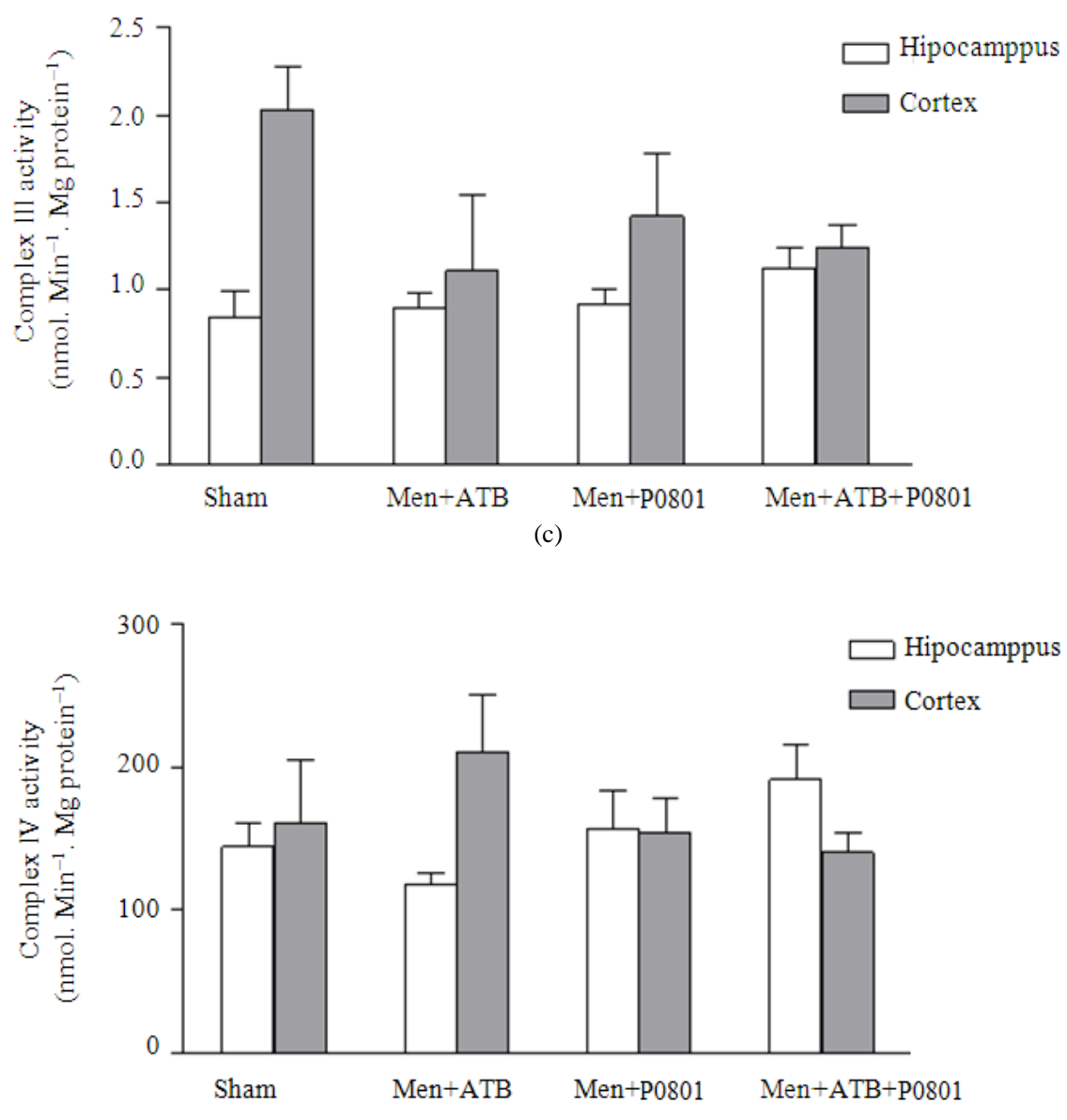

(d)

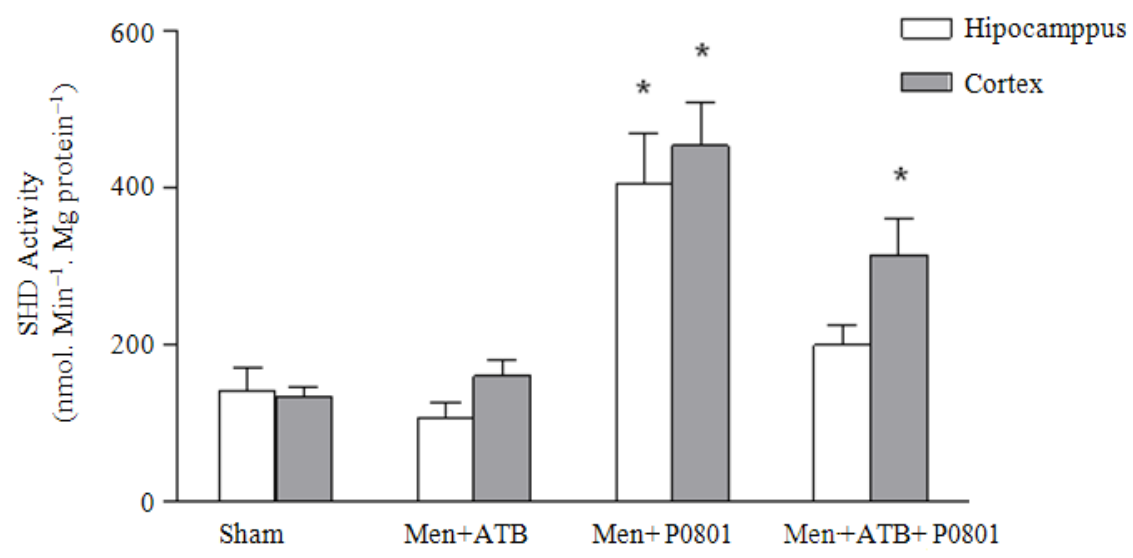

(e)

Fig. 4: Activity of complexes I (A), II (B), III (C), IV (D) and SDH (E) in the hippocampus and cerebral cortex of rats after pneumococcal meningitis that received antibiotic therapy or antioxidant treatment with P0801 at $48 \mathrm{~h}$ after induction of meningitis. Results are expressed as mean \pm S.D. of 5-7 animals in each group. Symbols indicate statistically significant when compared with sham group * $\mathrm{p}<0.05$ 
Am. J. Pharm. \& Toxicol., 7 (2): 49-61, 2012

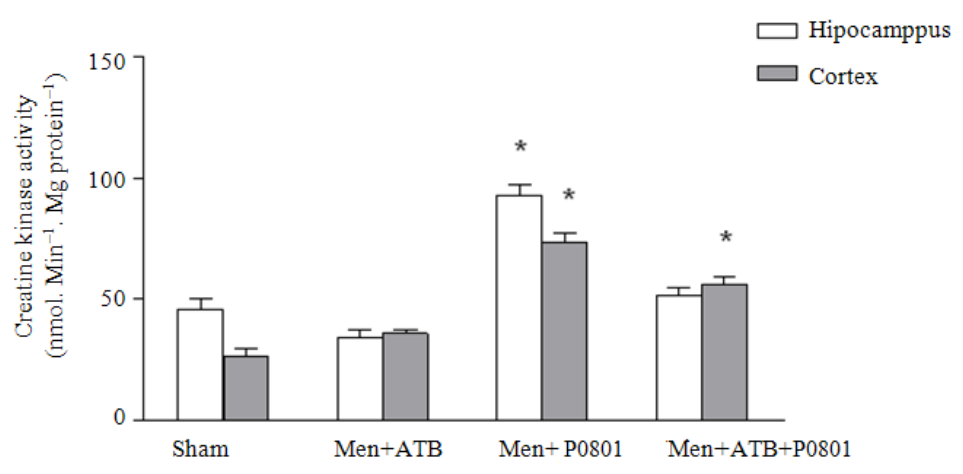

(a)

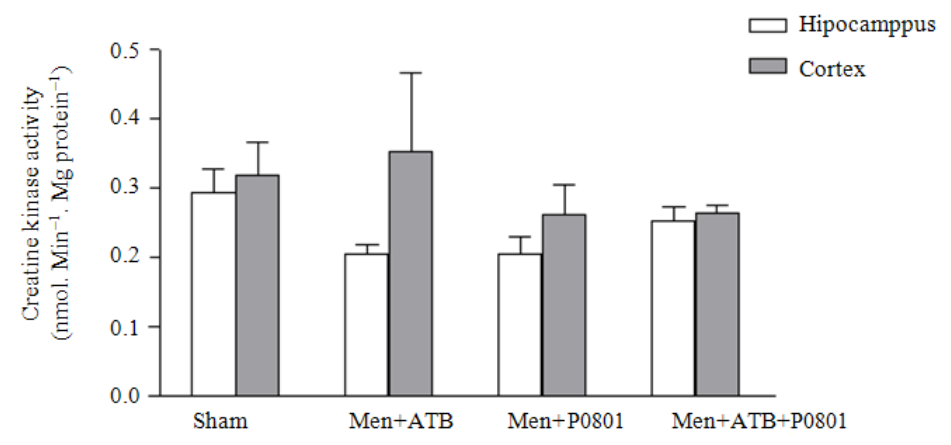

(b)

Fig. 5: Creatine Kinase (CK) activity in hippocampus and cerebral cortex of rats after pneumococcal meningitis that received antibiotic therapy or antioxidant treatment with P0801 at $24 \mathrm{~h}$ (A) and $48 \mathrm{~h} \mathrm{(B)}$ after induction of meningitis. Results are expressed as mean \pm S.D. of 5-7 animals in each group. Symbols indicate statistically significant when compared with sham group *p $<0.05$

The activity of enzyme succinate dehydrogenase (SHD) was increased in cerebral cortex in the group that received antioxidant treatment at $24 \mathrm{~h}$ after induction meningitis (Fig. 3e), being that in $48 \mathrm{~h}$ was increased in the hippocampus also, being in this time increased in cerebral cortex in the group that received antibiotic therapy and antioxidant treatment (Fig 4e).

In the CK activity was increased in hippocampus and cerebral cortex at $24 \mathrm{~h}$ after induction meningitis in the group that received antioxidant treatment and only in cerebral cortex in the group that received antibiotic therapy with antioxidant treatment (Fig. 5a). At $48 \mathrm{~h}$ there was not altered in the CK activity (Fig. 5b).

\section{DISCUSSION}

Several experimental studies over the past few years have documented that bacterial meningitis cause cell damage in two areas of the brain: the cortex and the hippocampus (Leib et al., 2000; Pfister et al., 2000; Loeffler et al., 2001). Other studies have shown that apoptosis in the hippocampus and cortical necrosis due to pneumococcal meningitis also contribute to damage brain (Grandgirard et al., 2007; Irazuzta et al., 2008). In pneumococcal meningitis, the inflammation caused by the organism increases the production of polymorphonuclear leukocytes causing bacterial cell lysis and, simultaneously, the leukocytes enhance release of proteolytic metabolites such as ROS, resulting in endothelial damage and increased permeability of the BBB (Waggener, 1974; Kontos et al., 1992). With the generation of ROS in the brain of rats with pneumococcal meningitis, brain energy metabolism may be compromised by the high dependence of ATP in the CNS. The formation of ROS can cause mitochondrial damage, impairing oxidative phosphorylation and limiting the production of ATP (Sen et al., 2007). Ghielmetti et al. (2003) showed that the level of ATP and ADP were decreased in the cerebral cortex by approximately $25 \%$ in rats affected by pneumococcal meningitis. 
Barichello et al. (2010a) reported that in the animals infected with meningitis and untreated with antibiotic therapy, the levels of lipid peroxidation and protein carbonyls in the hippocampus and cortex were increased at 24 and $48 \mathrm{~h}$ after induction of meningitis. In comparison, the meningitis animals that received antibiotic therapy responded differently, the lipid peroxidation and protein carbonyls were decreased in the hippocampus and cortex at 24 and $48 \mathrm{~h}$ after induction. In spite of effective antimicrobial therapy and intensive care, the outcome of pneumococcal meningitis remains poorly with a mortality rate of up to $30 \%$ and permanent sequel due to neuronal injury in up to 50\% of the survivors (Beek et al., 2004; Weisfelt et al., 2006). Success in the treatment of patients with bacterial meningitis and the development of improved strategies for disease management rely on knowledge of key pharmacologic principles for use of antimicrobial agents that are efficacious in the unique environment of the CSF, including penetration of the drug across the $\mathrm{BBB}$, the activity of the drug in purulent CSF and the intrinsic pharmacodynamic properties of the drug (Sinner and Tunkel, 2004).

In our study, the group of animals with pneumococcal meningitis that received antioxidant treatment with new compound P0801, with or without antibiotic therapy at $24 \mathrm{~h}$ after induction decreased protein carbonyls in cerebral cortex and in the hippocampus at $48 \mathrm{~h}$ after induction. In the group that received only antioxidant treatment increased lipid peroxidation in the cerebral cortex at $24 \mathrm{~h}$ after induction meningitis, however, in the hippocampus at $48 \mathrm{~h}$ after induction meningitis decreased lipid peroxidation. The antibiotic therapy with antioxidant treatment can be studied as a potential treatment for bacterial meningitis, since it appears to decrease the oxidative stress.

The formation of oxidative stress may participate in the neuroinflammatory process and cause mitochondrial abnormalities, inhibiting the action of respiratory chain enzymes and decreasing the energy metabolism (Mancuso et al., 2006; Sayre et al., 2008). In this context, Barichello et al. (2010b) evaluated the activities of mitochondrial respiratory chain complexes in the brain of rats submitted to meningitis by $S$. pneumoniae. The results demonstrated that the activity of complex I was inhibited only $24 \mathrm{~h}$ after induction of meningitis in the structures striatum, cerebellum and hippocampus. The activities of complex II, III e IV were increased in the brain structures at 24 and $48 \mathrm{~h}$ after induction meningitis. In fact, a number of devastating neurodegenerative disorders are associated with complex I deficiency, resulting in a decline of energy production by the respiratory chain and in increased production of Reactive Oxygen Species (ROS) (Bailey et al., 2005; DiMauro and Hirano, 2005; Petrosillo et al., 2008). In our results, in the animals with pneumococcal meningitis that received antibiotic therapy and or antioxidant treatment with new compound P0801 at $24 \mathrm{~h}$ after induction of meningitis, there were increased of the activity of complex I, II, IV and enzyme succinate dehydrogenase in cerebral cortex, being that at $48 \mathrm{~h}$ in the group that received antibiotic therapy and or antioxidant treatment there were increased of the activity of complex I, II and enzyme succinate dehydrogenase in the cerebral cortex and or hippocampus.

Barichello et al. (2009) verified that $24 \mathrm{~h}$ after the induction of the meningitis were observed a decrease in CK activity, being that at $48 \mathrm{~h}$ after meningitis, the CK activity was not altered. In our study, the CK activity was increased in hippocampus and cerebral cortex at $24 \mathrm{~h}$ after induction meningitis in the group that received antioxidant treatment and only in cerebral cortex in the group that received antibiotic therapy with antioxidant treatment.

Animal studies have shown that treatment antioxidants may protect against brain damage resulting from bacterial meningitis (Christen et al., 2001; Halliwell and Gutteridge, 2007). Klein et al. (2006) shows that the treatment antioxidant with NAC (nacetylcysteine) to be one promising therapeutic agent because it reduced both cerebral and cochlear complications of experimental pneumococcal meningitis. The study with new compound is an attempt to coadjuvant treatment with the antibiotic to minimize the oxidative damage and energy metabolism during illness.

\section{CONCLUSION}

Antibiotic treatment of pneumococcal meningitis with new compound antioxidants may be promising as a coadjuvant treatment by minimizing the damage effects of disease.

In our studies, the new compound seems to minimize oxidative stress and energy metabolism caused by meningitis, which together with the antibiotic can contribute to an effective treatment, decreasing any risk of sequelae due to meningitis. However, New studies are needed to clarify the action of this new compound as coadjuvant, evaluating side effects and their formulation, since it might look promising in the development of novel therapeutic agents in further studies. 


\section{ACKNOWLEDGEMENT}

This research was supported by grants from CNPq, FAPESC, UNESC and Instituto Nacional de Ciência e Tecnologia Translacional em Medicina (INCT).

\section{REFERENCES}

Bailey, S.M., A. Landar and V. Darley-Usmar, 2005. Mitochondrial proteomics in free radical research. Free Radic. Biol. Med., 38: 175-188. DOI: 10.1016/j. freeradbiomed. 2004.10.011

Baraff, L.J., S.I. Lee and D.L. Schriger, 1993. Outcomes of bacterial meningitis in children: A meta-analysis. Pediatr. Infect. Dis. J., 12: 389-394. PMID: 8327300

Barichello, T., G.D. Savi, G.Z. Silva, J.S. Generoso and G. Bellettini, 2010a. Antibiotic therapy prevents, in part, the oxidative stress in the rat brain after meningitis induced by Streptococcus pneumoniae. Neurosci. Lett., 478: 93-96. DOI: 10.1016/j.neulet.2010.04.072

Barichello, T., G.D. Savi, L.R. Simões, J.S. Generoso and D.B. Fraga, 2010b. Evaluation of mitochondrial respiratory chain in the brain of rats after pneumococcal meningitis. Brain Res. Bull., 82: 302-307. DOI: $10.1016 / \mathrm{j}$. brainresbull. 2010.05.012

Barichello, T., G.Z. Silva, G.D. Savi, J.M. Torquato and A.L. Batista et al., 2009. Brain Creatine kinase activity after meningitis induced by Streptococcus pneumoniae. Brain Res. Bull., 80: 85-88. DOI: 10.1016/j. brainresbull. 2009.04.011

Bedford, H., J.D. Louvois, S. Halket, C. Peckham and R. Hurley et al., 2001. Meningitis in infancy in England and Wales: Follow up at age 5 years. BMJ, 323: 533-536. DOI: $10.1136 / \mathrm{bmj}$. 323.7312 .533

Beek, D.V.D., B. Schmand, J. De Gans, M. Weisfelt and H. Vaessen et al., 2002. Cognitive impairment in adults with good recovery after bacterial meningitis. J. Infect. Dis., 186: 1047-1052. DOI: $10.1086 / 344229$

Beek, D.V.D., J.D. Gans, L. Spanjaard, M. Weisfelt and J.B. Reitsma et al., 2004. Clinical features and prognostic factors in adults with bacterial meningitis. N. Engl. J. Med., 351: 1849-1859. DOI: 10.1056/NEJMoa040845

Bellac, C.L., R.S. Coimbra, F. Simon, H. Imboden and S.L. Leib, 2007. Gene and protein expression of galectin-3 and galectin-9 in experimental pneumococcal meningitis. Neurobiol. Dis., 28: 175-183. DOI: $10.1016 /$ j. nbd. 2007.07.005
Bellac, L.C., R.S. Coimbra, S. Christen and S.L. Leib, 2006. Pneumococcal meningitis causes accumulation of neurotoxic kynurenine metabolites in brain regions prone to injury. Neurobiol. Dis., 24: 395-402. DOI: 10.1016/j. nbd. 2006.07.014

Brandt, C.T., 2010. Experimental studies of pneumococcal meningitis. Dan. Med. Bull., 57: 4119. PMID: 20175949

Cassina, A. and R. Radi, 1996. Differential inhibitory action of nitric oxide and peroxynitrite on mitochondrial electron transport. Arch. Biochem. Biophys., 328: 309-316. DOI: 10.1006/Abbi. 1996.0178

Christen, S., M. Schaper, J. Lykkesfeldt, C. Siegenthaler and Y.D. Bifrare et al., 2001. Oxidative stress in brain during experimental bacterial meningitis: Differential effects of $\alpha$ phenyl-tert-butyl nitrone and $\mathrm{N}$-acetylcysteine treatment. Free Radic. Biol. Med., 31: 754-762. DOI: 10.1016/S0891-5849 (01)00642-6

Cuzzocrea, S., D.P. Riley, A.P. Caputi and D. Salvemini, 2001. Antioxidant therapy: A new pharmacological approach in shock, inflammation, and ischemia/reperfusion injury. Pharmacol. Rev., 53: 135-159.

DiMauro, S. and M. Hirano, 2005. Mitochondrial encephalomyopathies: An update. Neuromuscul. Disord., 15: 276-286. PMID: 15792866

Draper, H.H. and M. Hadley, 1990. Malondialdehyde determination as index of lipid peroxidation. Methods Enzymol., 186: 421-431. DOI: 10.1016/0076-6879 (90)86135-I

Fischer, J.C., W. Ruitenbeek, J.A. Berden, J.M. Trijbels and J.H. Veerkamp et al., 1985. Differential investigation of the capacity of succinate oxidation in human skeletal muscle. Clin. Chim. Acta., 153: 23-36. DOI: 10.1016/0009-8981 (85)90135-4

Ghielmetti, M., H. Ren, S.L. Leib, M.G. Täuber and S. Christen, 2003. Impaired cortical energy metabolism but not major antioxidant defenses in experimental bacterial meningitis. Brain Res., 976: 139-148. DOI: 10.1016/S0006-8993 (03)02557-5

Grandgirard, D., O. Steiner, M.G. Tauber and S.L. Leib, 2007. An infant mouse model of brain damage in pneumococcal meningitis. Acta Neuropathol., 144: 609-617. DOI: 10.1007/s00401007-0304-8

Grimwood, K., V.A. Anderson, L. Bond, C. Catroppa and R.L. Hore et al., 1995. Adverse outcomes of bacterial meningitis in school-age survivors. Pediatrics, 95: 646-656. PMID: 7536915 
Halliwell, B. and J.M.C. Gutteridge, 2007. Free Radicals in Biology and Medicine. 4th Edn., Oxford University Press, Oxford, New York, ISBN-10: 019856869X, pp: 851.

Hoogman, M., D.V.D. Beek, M. Weisfelt, J.D. Gans and B. Schmand, 2007. Cognitive outcome in adults after bacterial meningitis. J. Neurol. Neurosurg. Psychiatry., 78: 1092-1096. DOI: 10.1136/jnnp.2006.110023

Hughes, B.P., 1962. A method for the estimation of serum Creatine kinase and its use in comparing Creatine kinase and aldolase activity in normal and pathological sera. Clin. Chim. Acta., 7: 597-603. DOI: 10.1016/0009-8981 (62)90137-7

Irazuzta, J., R.K. Pretzlaff and B. Zingarelli, 2008. Caspases inhibition decreases neurological sequelae in meningitis. Crit. Care. Med., 36: 16031606. DOI: 10.1097/CCM.0b013e318170ab08

Klein, M., U. Koedel and H.W. Pfister, 2006. Oxidative stress in pneumococcal meningitis: A future target for adjunctive therapy? Prog. Neurobiol., 80: 269280. DOI: $10.1016 /$ j.pneurobio.2006.11.008

Koedel, U., W.M. Scheld and H.W. Pfister, 2002. Pathogenesis and pathophysiology of pneumococcal meningitis. Lancet Infect. Dis., 2: 721-736. DOI: 10.1016/S1473-3099 (02)00450-4

Kontos, C.D., E.P. Wei, J.I. Williams, H.A. Kontos and J.T. Povlishock, 1992. Cytochemical detection of superoxide in cerebral inflammation and ischemia in vivo. Am. J. Physiol., 263: 1234-1242. PMID: 1329563

Leib, S.L., D. Leppert, J. Clements and M.G. Tauger, 2000. Matrix metalloproteinases contribute to brain damage in experimental pneumococcal meningitis. Infect. Immun., 68: 615-620. DOI: 10.1128/IAI.68.2.615-620.2000

Levine, R.L., D. Garland, C.N. Oliver, A. Amici and I. Climent et al., 1990. Determination of carbonyl content in oxidatively modified proteins. Methods Enzymol., 186: 464-478. DOI: 10.1016/00766879(90)86141-H

Loeffler, J.M., R. Ringer, M. Hablutzel, M.G. Tauber and S.L. Leib, 2001. The free radical scavenger $\alpha$ phenyl-tert-butyl nitrone aggravates hippocampal apoptosis and learning deficits in experimental pneumococcal meningitis. J. Infect. Dis., 183: 247252. DOI: $10.1086 / 317921$

Lowry, O.H., N.G. Rosebough, A.L. Farr and R.J. Randall, 1951. Protein measurement with the Folin phenol reagent. J. Biol. Chem., 193: 265-275.
Mancuso, M., F. Coppede, L. Migliore, G. Siciliano and L. Murri, 2006. Mitochondrial dysfunction, oxidative stress and neurodegeneration. J. Alzheimers Dis., 10: 59-73. PMID: 16988483

Merkelbach, S., H. Sittinger, I. Schweizer and M. Muller, 2000. Cognitive outcome after bacterial meningitis. Acta Neurol. Scand., 102: 118-123. DOI: 10.1034/j.1600-0404.2000.102002118.x

Ostergaard, C., R.V. Yieng-Kow, T. Benfield, N. Frimodit-Moller and F. Espersen et al., 2000. Inhibition of leukocyte entry into the brain by the selection blocker fucoidin decreases interleukin-1 (IL-1) levels but increases IL-8 levels in cerebrospinal fluid during an experimental pneumococcal meningitis in rabbits. Infect. Immun., 68: 31533157. DOI: 10.1128/IAI.68.6.3153-3157.2000

Petrosillo, G., M. Matera, G. Casanova, F.M. Ruggiero and G. Paradies, 2008. Mitochondrial dysfunction in rat brain with aging: Involvement of complex I, reactive oxygen species and Cardiolipin. Neurochem. Int., 53: 126-131. DOI: 10.1016/j.neuint.2008.07.001

Pfister, L.A., J.H. Tureen, S. Shaw, S. Christen and D.M. Ferriero et al., 2000. Endothelin inhibition improves cerebral blood flow and is neuroprotective in pneumococcal meningitis. Ann. Neurol., 47: 329-335. DOI: 10.1002/15318249(200003)47:3<329::AID-ANA8>3.0.CO;2-R

Quagliarello, V.J., B. Wispelwey, W.J. Long Jr. and W.M. Scheld, 1991. Recombinant Human Interleukin-1 Induces Meningitis and Blood-Brain Barrier Injury in the Rat. Characterization and comparison with tumor necrosis factor. J. Clin. Invest., 87: 1360-1366. PMID: 2010549

Rustin, P., D. Chretien, T. Bourgeron, B. Gerard and A. Rotig et al., 1994. Biochemical and molecular investigations in respiratory chain deficiencies. Clin. Chim. Acta, 228: 35-51. DOI: 10.1016/00098981 (94)90055-8

Sayre, L.M., G. Perry and M.A Smith, 2008. Oxidative stress and neurotoxicity. Chem. Res. Toxicol., 21: 172-188. DOI: $10.1021 / \mathrm{tx} 700210 \mathrm{j}$

Scheld, W.M., U. Koedel, B. Nathan and H.W. Pfister, 2002. Pathophysiology of bacterial meningitis: mechanism(s) of neuronal injury. J. Infect. Dis., 186: 225-233. DOI: 10.1086/344939

Sen, T., N. Sen, S. Jana, F.H. Khan and U. Chatterjee et al., 2007. Depolarization and Cardiolipin depletion in aged rat brain mitochondria: Relationship with oxidative stress and electron transport chain activity. Neurochem. Int., 50: 719-725. DOI: 10.1016/j.neuint.2007.01.007 
Sinner, S.W. and A.R. Tunkel, 2004. Antimicrobial agents in the treatment of bacterial meningitis. Infect Dis. Clin. North. Am., 18: 581-602. DOI: 10.1016/j.idc. 2004.04.005

Waggener, J.D., 1974. The pathophysiology of bacterial meningitis and cerebral abscesses: An anatomical interpretation. Adv. Neurol., 6: 1-17. PMID: 4614651
Weisfelt, M., D.V.D. Beek, L. Spanjaard, J.B. Reitsma and J.D. Gans, 2006. Clinical features, complications, and outcome in adults with pneumococcal meningitis: a prospective case series. Lancet Neurol., 5: 123-129. DOI: 10.1016/S1474-4422 (05)70288-X 